\title{
UM PAÍS SEM MEMÓRIA?: O PERIGO PARA OS FUTUROS PESQUISADORES COM A NÃO CUSTÓDIA DAS INFORMAÇÕES DAS REDES SOCIAIS VIRTUAIS DO GOVERNO BRASILEIRO.
}

\author{
Eliezer Pires da Silva \\ UNIRIO \\ eliezerpires@gmail.com
}

Diogo Baptista Pereira ${ }^{1}$

UNIRIO

pereira.diogo@outlook.com

Resumo

Este artigo vem provocar o debate da necessidade de se pensar uma política pública voltada para a preservação do conteúdo postado online pelos órgãos federais nas redes sociais virtuais e apresentar que riscos podem ocasionar para o futuro pesquisador, tendo em vista o crescente uso por parte do governo brasileiro.

Palavras-chave: Informação. Custódia. redes sociais.

\section{A COUNTRY WITHOUT MEMORY ?: THE DANGER FOR FUTURE RESEARCHERS WITH THE NO CUSTODY OF INFORMATION IN VIRTUAL SOCIAL NETWORKS FROM THE BRAZILIAN GOVERNMENT'S}

\begin{abstract}
This article provokes the debate on the need to think about a public policy aimed at preserving the content posted online by federal agencies on virtual social networks and presenting what risks may pose to the future researcher, given the growing use by the government brazilian.
\end{abstract}

Keywords: Information. custody. social networks.

\footnotetext{
${ }^{1}$ Mestre no Programa de Pós-Graduação de Gestão de Documentos e Arquivos - UNIRIO. Possui bacharelado e licenciatura em História pela Universidade Federal Fluminense - UFF, bacharelado em Arquivologia pela Universidade Federal do Estado do Rio de Janeiro - UNIRIO. Coordenador de comunicação do Diretório Acadêmico de Arquivologia da UNIRIO (Gestão 2017-2018).

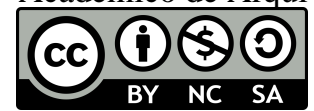




\section{INTRODUÇÃO}

A internet deixou de ser apenas um canal em que o mensageiro se comunicava com o receptor para se tornar um lugar no qual o receptor também se tornasse mensageiro. Nos últimos anos, constituiu-se também como um espaço mais amplo para debater e discutir ideias e opiniões.

Em 2008, a forma de se fazer marketing eleitoral foi modificada com a campanha de Barack Obama à Presidência dos Estados Unidos. Com uma forma mais interativa e nova de fazer política, a campanha se utilizou bastante das redes sociais virtuais para construir a imagem do candidato, propagar as ideias do partido democrata para o mandato 2009-2013, além de interagir "diretamente" com o eleitorado, criando laços $(\mathrm{G} 1,2010)$. O eleitor se viu diante de mais um meio para se tornar mais ativo, participativo. Além de ser também um meio de o candidato conhecer o eleitorado e elaborar propostas para um perfil específico, pois algumas redes sociais permitem que você saiba dados como sexo, idade, local e religião dos usuários.

Após eleito, Barack Obama, continuou com o uso das redes sociais. A Casa Branca passou a ter outro canal de comunicação que não fosse o sítio eletrônico, um porta-voz ou anúncios do presidente para o país. O Arquivo Nacional dos Estados Unidos -National Archives and Record Administration (NARA) - mantém a guarda das contas das publicações oficiais da Casa Branca durante a gestão do governo Obama, entre 2009-2017, no Twitter, Facebook, Instagram, Medium, Flickr e Tumblr. Em outras palavras, o uso das redes sociais virtuais é muito relevante, ao ponto de o governo dos Estados Unidos as utilizar como veículo de comunicação e também de ter a custódia desse acervo online mantido pelo Arquivo Nacional (NARA) do seu país (OBAMAWHITE.GOV, 2017).

Nas últimas eleições presidenciais no Brasil viu-se que o tempo televisivo na Propaganda Eleitoral Gratuita não foi tão decisivo para a escolha do Presidente da República e que as redes sociais virtuais tiveram uma maior influência na decisão. O WhatsApp foi um dos canais mais utilizados para propagação de notícias (falsas) sobre os adversários. O jornal Folha de São Paulo chegou a denunciar disparos de mensagens de empresas que obtinham dados de seus clientes e estes eram oferecidos e vendidos aos candidatos. Esta estratégia teria beneficiado o então candidato e atual presidente, Jair Bolsonaro (MELLO, 2019).

Após eleito Presidente da República, o governo Bolsonaro apagou todas as publicações feitas pelos governos anteriores nas redes sociais. Ou seja, não há nada dos governos Lula, Dilma, Temer e suas decisões e comunicações oficiais (nas plataformas virtuais) com a sociedade civil, inclusive as respostas, críticas, elogios e cobranças feitas nas postagens. 
Apagou-se todo um material de tomadas de decisões e opiniões do passado do país. Os posicionamentos e decisões anunciadas pelos governantes geram impacto na economia, sociedade, política etc.

Este artigo tem por objetivo debater a importância das redes sociais virtuais enquanto meio de informação e sua influência na memória do país e das ações do governo, e questionar se: Não está no momento de criarmos uma política de custódia das contas das redes sociais virtuais (Facebook, Twitter, YouTube etc.) da Presidência da República após o fím de seu mandato para a preservação da memória do país?

A metodologia para tentar responder essa pergunta ou ao menos suscitar e aprofundar esse tema passa pelo debate do conceito de informação e de memória; entender as possibilidades das redes sociais virtuais atualmente, o grau de associação dos usuários e o alcance dessas ferramentas.

\section{COGNITIVISMO E INFORMAÇÃO}

O cognitivismo é muito referenciado nas áreas da educação e da psicologia. Possui uma abordagem interacionista. Tem uma relação com o estudo da mente, "o ato de conhecer; como o homem desenvolve seu conhecimento acerca do mundo, analisando os aspectos que intervêm no processo "estímulo/reposta" (SANTOS, 2006, p. 100). Na perspectiva cognitivista, o conhecimento é construído. Por fim, "enfatiza os processos mentais, dando atenção aos modos de atribuição do significado, compreensão, armazenamento e utilização da informação envolvida" (FALCI, 2017, p. 33).

A abordagem cognitiva entra no campo da CI como uma crítica às abordagens objetivistas já estabelecidas. Foi uma verdadeira revolução, fazendo com que os estudos da CI se voltassem de modo mais sistemático aos usuários e suas necessidades. [...]

O cognitivismo parte da noção que nossa aprendizagem, o modo como lidamos com o que nos cerca, nosso entendimento, é mediado por modelos mentais, constituídos em nossa estrutura cognitiva. Dito de outro modo, são modelos abstratos com relações de conceitos, naturalmente construídos a partir de nosso sistema nervoso e das experiências que temos durante nossa vida. Esta estrutura não deixa de ser uma memória, que terá privilégio nos estudos das ciências cognitivas (FERNANDES, 2011, p. 52).

Em 1948, Claude Shannon, matemático, escreve um artigo em que apresenta os problemas na comunicação. Conforme o autor, para evitar que ocorra entropia em uma comunicação é preciso diminuir os ruídos em uma comunicação entre as partes envolvidas. Assim, garantindo um maior sucesso do envio do emissor para o receptor. Segundo Shannon 
(1948, p.1), o problema fundamental da comunicação "é o de reproduzir em um ponto exatamente ou aproximadamente uma mensagem selecionada em outro ponto". Para confirmar que a mensagem original foi entendida da maneira correta pelo receptor, este teria de dar o retorno (feed-back).

Imagem 1 - Diagrama esquemático de um sistema de comunicação

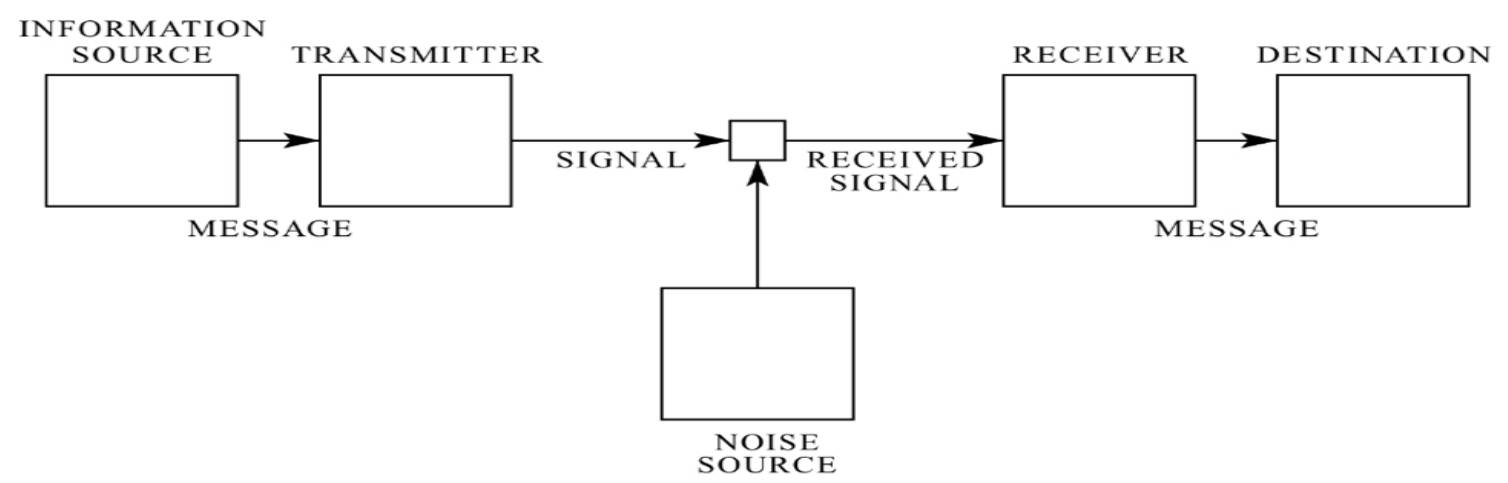

Fonte: Shannon (1948, p. 2).

O termo "informação" é muito estudado por diversos autores e até hoje não se chegou a uma definição unificada devido às suas diversas facetas e aos entendimentos que variam de acordo com áreas do conhecimento. O conceito e aplicação do termo são diferentes nas ciências humanas e sociais, nas ciências naturais, na ciência da informação etc. A informação é um conceito interdisciplinar e polissêmico.

Segundo Capurro (2007, p.159), se antes a palavra informação significava dar forma, "moldado por", com o passar do tempo passou a ser "recebido de". Passou de algo material para algo mais abstrato, como a mente.

Dito isso, a informação que é construída nos espaços das redes sociais, ao que tange a esfera governamental, caracteriza-se como um acervo de interesse público e que é de responsabilidade do estado de gestar e preservar para que haja o acesso futuro.

\section{MEDIAÇÃO DA INFORMAÇÃO}

Partindo da premissa de que não existe neutralidade, pois em todas as nossas atitudes, carregamos conosco teorias e pensamentos que adquirimos ao longo de nossa existência. Tudo o que pensamos, escrevemos, decidimos é fruto de uma interseção social, das leituras que adquirimos, da educação que tivemos e dos acontecimentos e fatos que vivemos e como se 
gravaram em nosso cognitivo. O homem é fruto do contexto em que ele se encontra, do espaçotempo que ocupa. É preciso estar consciente disso para evitar uma manipulação na informação.

Em oposição ao pensamento hegemônico que sustenta a imparcialidade e a neutralidade do profissional da informação no exercício de seu trabalho, defendemos a existência da interferência. É ela constante e indissociada do fazer do profissional da informação.

[...] A informação está imersa em ideologias e em nenhuma hipótese se apresenta desnuda de interesses, sejam econômicos, políticos, culturais, etc. (ALMEIDA JÚNIOR, 2009, p. 93).

Uma publicação pode ter, por exemplo, cunho político, utilizando-se de uma visão de um fato para rememorar ou comemorar uma data, um evento, etc. Não há neutralidade nessa publicação e, sim, uma intenção. Nesse momento podem aparecer embates/controvérsias entre atores (usuários) que se "associaram" virtualmente àquele canal de comunicação. Há também aqueles que não gostam do (conteúdo e da forma) que é publicado e resolvem se "desassociar" (deixando de curtir/seguir a página), pois é muito usual diferentes tipos de reações numa postagem. Uns curtem, outros criticam, uns debatem e comentam, uns bloqueiam, outros compartilham e há também os que convidam amigos para participar e assim por diante.

Para Almeida Junior (2009), a existência da informação se faz a partir do momento em que o usuário tem contato com o conteúdo. Isso porque, para o autor, ocorre uma modificação, uma mudança, uma transformação do conhecimento, passando o usuário a ser coprodutor da informação.

Em síntese, a pesquisa defende que a informação é efêmera e se concretiza apenas no momento em que se dá a relação do usuário com o suporte que torna possível a existência dela, informação. Não existe antes da relação usuário/suporte, o que redunda em defendermos que o profissional da informação trabalha como uma informação latente, uma quase-informação. Preferimos chamá-la de proto-informação, uma vez que ela não é, ainda, uma informação (ALMEIDA JÚNIIOR, 2009, p. 98).

Sob essa perspectiva, quem decide o que é ou não informação é o usuário. Ele deixa de ser apenas um receptor da mensagem para se tornar também um agente influenciador da mesma. O cognitivo de cada um é que definirá a informação. O usuário é ativo e não passivo na informação.

Buckland (1991) distinguiu informação em três aspectos: "informação-como-processo"; "informação-como-conhecimento"; "informação-como-coisa". O primeiro se dá quando alguém é informado, é o ato de informar; o segundo é usado para mostrar o que é percebido da informação recebida, é o que se entende ; o terceiro é utilizado para objetos (dados, documentos, 
registro, texto, filme, representatividade de alguma coisa) (BUCKLAND, 1991). A “informação-como-conhecimento" é um processo mental, é intangível, e a "informação-comocoisa" é algo material, tangível, físico.

Embora, o documento digital possua um suporte físico, pois há um HD, servidor etc., suas informações não são tangíveis como em um documento em suporte de papel. São códigos binários em 0 e 1 e que só são lidos mediantes a mediação de um ser humano com aportes tecnológicos.

\section{TEORIA DAS REDES}

[A Teoria de redes] pode ser entendida como uma análise complexa das interações entre os atores envolvidos, atores que podem ser pessoas, organizações, meio ambiente, a partir do instante em que haja algum tipo de troca entre eles, sendo tangíveis (bens, materiais) ou intangíveis (ideias, valores) (FERREIRA; VITORINO, 2010, p.2, grifo nosso).

O termo "redes" percorre áreas do conhecimento como a Sociologia, a Antropologia, Filosofia, Comunicação, Geografia, Ciência da computação, etc. Para Acioli (2007, p.3) "trabalhar com a ideia de redes significa trabalhar, de forma articulada, com a ideia de informação" e que a noção de redes/redes sociais teria nascido na Antropologia Social. O estudo dessa temática começou na década de 1970, "quando antropólogos e sociólogos buscaram compreender como os indivíduos estão conectados uns aos outros e como essas afiliações servem como uma 'cola' ou mantêm o significado da vida social” (LOPES; BALDI, 2009, p. 1011). Marteleto (2001, p. 72) usa a seguinte definição para redes sociais:

[...]sistema de nodos e elos; uma estrutura sem fronteiras; uma comunidade não geográfica; um sistema de apoio ou um sistema físico que se pareça com uma árvore ou uma rede. A rede social, derivando deste conceito, passa a representar um conjunto de participantes autônomos, unindo ideias e recursos em torno de valores e interesses compartilhados.

Há mais de uma forma de interação entre os atores, essa interação pode se diferenciar conforme o canal utilizado para a comunicação. Um ator pode acabar levando vantagem sobre outro e isso pode variar segundo a rede social utilizada. Em outras palavras, é necessário analisar como se dá a relação do ator com a estrutura. A vantagem que um ator pode exercer sobre o outro vai além de apenas passar um conteúdo e oferecer pouca interação, mas, sobretudo, configura-se em obter conteúdo, informações de outro ator (idade, localização, sexo, pessoas com quem o ator se relaciona etc.). 
Baran (1964) apresenta, por meio de um diagrama, algumas formas de redes: centralizada, descentralizada e distribuída. Ver exemplo na imagem 2.

Imagem 2 - Rede centralizada, descentralizada e distribuída
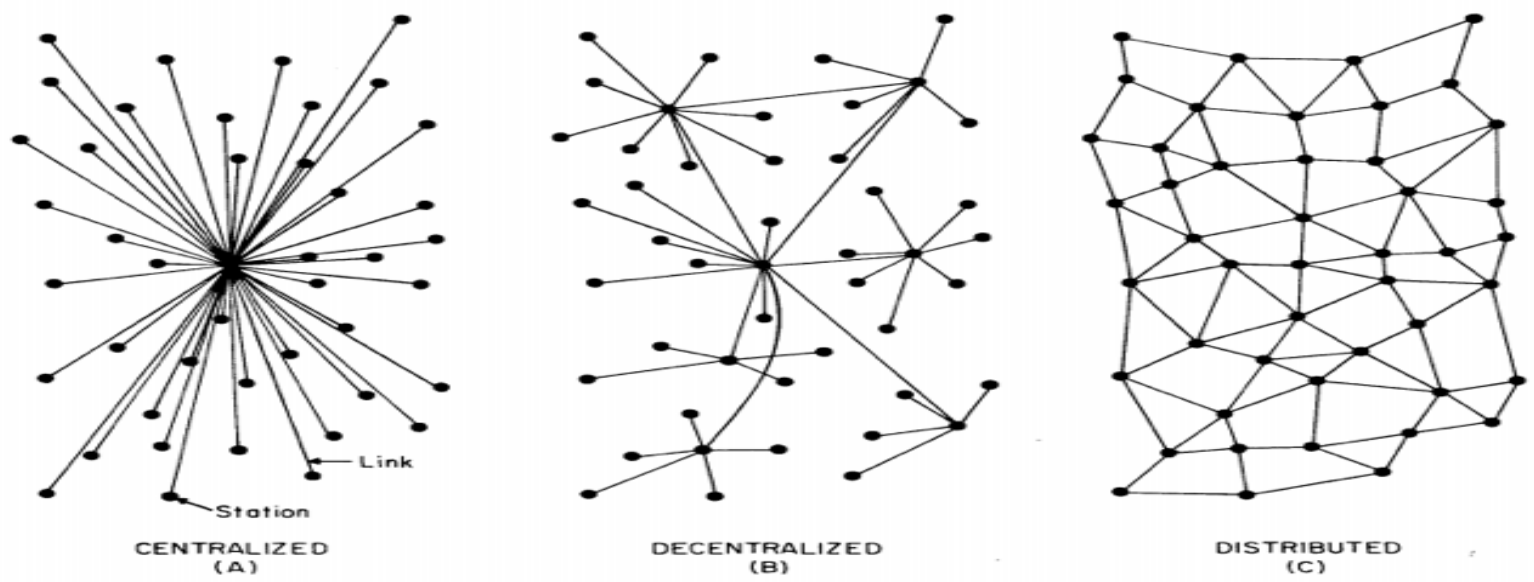

FIG. I - Centralized, Decentralized and Distributed Networks

Fonte: Baran (1964 p. 2).

No exemplo (A) da imagem 2, está representada uma rede centralizada. Há um ator que distribui a informação aos demais atores. Nela há maior relação de poder, pois a informação está em posse desse único ator. No exemplo (B), ocorre uma relação desproporcional entre os atores (que chamaremos de "nós"). Há uma relação hierárquica, porém menor que a anterior, aqui mais de um ator detem a posse da informação. No exemplo (C), não há um ator central, ou seja, não há uma hierarquia dentro dessa rede, todos podem ser detentores da posse da informação.

Paul Baran (1964) aponta a fragilidade e a vulnerabilidade da rede centralizada, pois ela depende de um "nó" (ator) central. Caso esse "nó” seja destruído, tudo que estiver contido nele também será. Podemos aplicar isso a um sítio, por exemplo, as informações estão todas lá, sob o domínio de um único ator, o sítio eletrônico. Uma vez que esse sítio saia do ar, seja apagado ou reformulado, a informação contida nele simplesmente pode ser destruída e quem tinha acesso antes poderá perdê-lo, ou fazer o uso que bem entender das informações.

Albert-László Barabási e Eric Bonabeau (2003), em sua teoria de "rede sem escala", apontam que um ator (nó) poderá ter mais ligações que outros atores, não havendo uma aleatoriedade defendida por alguns autores. Tendo um ator mais ligações, há, então, um desequilíbrio de poder. Esse ator que tem muitas conexões tenderá a reforçar esses laços e aumentar sua interação, possuindo assim, mais ligações com outros atores. Estes são denominados de hubs (conectores). 
Algumas redes sociais sugerem novos "seguidores/amigos" baseadas nas conexões de cada ator. Essa sugestão pode ser devida e esse ator "pertencer" a um grupo numa rede social, por "seguir/curtir" interesses semelhantes, local etc. A essa estrutura, denominou-se rich get rich (ricos ficam mais ricos). Ou seja, quanto mais conexões um nó possui, maiores as chances de ele ter mais conexões" (RECUERO, 2005, p. 6).

Nem sempre a interação é perceptível. Uma pessoa pode “curtir/seguir" uma instituição em sua rede social virtual, porém manter uma interação unilateral e implícita, ou seja, carregando o conhecimento ou informação adquirida nas publicações sem ter que dar um retorno ao outro ator (seja com um like ou qualquer outro mecanismo que se apresente, tais como emoticons, onomatopeias, hashtags etc.). Não é preciso interagir diretamente com a publicação para estar ciente dela. Muitas redes sociais disponíveis online permitem que você possa ler postagem classificadas como públicas sem ter a necessidade de se associar.

A virtualizaçāo da comunicaçāo já existia em salas de bate-papo (chats) e correio eletrônico (e-mails), mas se intensificou ainda mais ao longo dos anos com o avanço de novas plataformas e tecnologias, como, por exemplo, o smartphone. Esse dispositivo possibilita responder praticamente no mesmo instante em que foi recebida uma mensagem e, por ser portátil, pode-se levá-lo a qualquer local.

\section{CONCLUSÃO}

Nora (1993) menciona os "lugares de memória” porque não há memória espontânea. Os locais de memória são importantes para sua preservação, seja em livros, estátuas, museus, tratados, monumentos aos mortos, comemoração de aniversários, atas etc. Sem esses a lembrança estaria apagada com o tempo.

À medida em que desaparece a memória tradicional, nós nos sentimos obrigados a acumular religiosamente vestígios, testemunhos, documentos, imagens, discursos, sinais visíveis do que foi, como esse dossiê cada vez mais prolifero devesse se tornar prova em não se sabe que tribunal da história (NORA, 1993, p. 15).

A memória com o tempo pode ganhar novos significados e não terá a mesmo interpretação para todos. Uma pessoa em dado momento pode ser para uns um herói e para outros um ditador. $\mathrm{O}$ aspecto cognitivo irá atuar, mesmo a memória tendo (em certa parte) uma construção coletiva. Políticos podem fazer um símbolo se perpetuar segundo os seus interesses 
e ideologias. De certa forma, a memória coletiva guarda fragmentos que ao serem reunidos podem contituir um momento da história.

As redes sociais virtuais facilitam a interação com o usuário. Nesse canal o usuário pode reclamar, elogiar, dar sugestões, marcar outra pessoa para ler a publicação feita pelo destinatário, como o governo etc. É possível aos governantes saber como aquela notícia foi recebida pela sociedade em geral e sua repercussão positiva ou negativa. O Senado Federal do Brasil tem utilizado a plataforma do Facebook para informes sobre leis aprovadas, em andamento e direitos adquiridos. Ou seja, tem usado para difundir e atualizar a sociedade civil com os trâmites dentro desta casa. E as pessoas costumam comentar sobre a lei ou projeto de lei dando suas opiniões e debatendo entre elas.

O pesquisador do futuro corre o risco de perder um riquíssimo material, fonte primária e de prova. Um print não garante a autenticidade do documento. Para o documento ser autêntico e realmente ele ser o que diz, é necessário ter seu conteúdo estável (e preservado), manter sua integridade, física e informacional, uma cadeia de custódia confiável desde sua criação. (INTERPARES 2 PROJECT, 2007).

A lei 8.159 de 1991, de arquivos, em seus dois artigos iniciais indica que,

\begin{abstract}
Art. $1^{\circ}$ - É dever do Poder Público a gestão documental e a proteção especial a documentos de arquivos, como instrumento de apoio à administração, à cultura, ao desenvolvimento científico e como elementos de prova e informação.

Art. $2^{\circ}$ - Consideram-se arquivos, para os fins desta Lei, os conjuntos de documentos produzidos e recebidos por órgãos públicos, instituições de caráter público e entidades privadas, em decorrência do exercício de atividades específicas, bem como por pessoa física, qualquer que seja o suporte da informação ou a natureza dos documentos. (BRASIL, 1991)
\end{abstract}

Mediante ao exposto, inferimos que é preciso ter subsídio teórico (literatura) e prático (pesquisa direto nas postagens e suas repercussões) para sustentar ou refutar a importância de se criar uma política de recolhimento e custódia das contas do Governo Federal para pesquisadores futuros e para a preservação da História do país e a solidificação de sua memória, além da transparência de seus atos.

Uma vez identificada a relevância de se preservar as postagens dos governos nas redes sociais virtuais, a quem caberia esse recolhimento: ao Arquivo Nacional do Brasil, assim como é feito nos Estados Unidos? Ou outra instituição? Através da simples transferência da conta para a guarda ou outra forma de custodiar os metadados?

\title{
REFERENCIAS
}


ACIOLI, Sonia. Redes sociais e teoria social: revelando os fundamentos do conceito. Informação \& Informação, Londrina, PR, v. 12, p.8-19, dez. 2007. Disponível em: $<$ http://www.uel.br/revistas/uel/index.php/informacao/article/view/1784>. Acesso em: 24 out. 2016.

ALMEIDA JÚNIOR, Oswaldo Francisco de. Mediação da informação e múltiplas linguagens. Tendências da Pesquisa Brasileira em Ciência da Informação, Brasília, DF, v. 2, n. 1, p.89-103, jan./dez. 2009.

BARABÁSI, Albert Lászlo; BONABEAU, Eric. Scale-free networks. Scientific American, [s.1.], v. 288, n. 5, p.50-50, maio 2003. Disponível em: 〈http://barabasi.com/f/124.pdf〉. Acesso em: 02 nov. 2016.

BARAN, Paul. On distributed communications: I. Introduction to distributed communications networks. Santa Monica: Rand Corporation, 1964. Disponível em: <https://www.rand.org/pubs/research_memoranda/RM3420.html>. Acesso em: 15 fev. 2016.

BRASIL. Lei n. 8159 de 9 de janeiro de 1991. Dispõe sobre a política nacional de arquivos públicos e privados e dá outras providências. Diário oficial da União, Brasília, DF, 29, n/6, p. 455 , jan. 1991.

BUCKLAND, M.K. Information as thing. Journal of the American Society for Information Science (JASIS), [s.1.], v.45, n.5, p.351-360, 1991.

CAPURRO, R.; HJORLAND, B. O conceito de informação. Perspectivas em Ciência da Informação, [s.1.], v. 12, n. 1, jan./abr. 2007.

FALCI, Samuel Henrique. Novas abordagens para detecção automática de aprendizagem. 2017. 82 f. Dissertação (Mestrado em Educação) -Universidade Federal dos Vales do Jequitinhonha e Mucuri, Diamantina, 2017. Disponível em:

<http://acervo.ufvjm.edu.br/jspui/bitstream/1/1657/1/samuel_henrique_falci.pdf >. Acesso em: 7 jun. 2018.

FERREIRA, Toniel; VITORINO, Valdir Antonio. Teoria de redes: uma abordagem social. Revista Conteúdo, Capivari, v. 1, n. 3, p.1-19, jul. 2010. Disponível em:

<http://www.conteudo.org.br/index.php/conteudo/article/viewFile/27/25>. Acesso em: 10 fev. 2015.

FERNANDES, Geni Chaves. Introdução à Ciência da Informação. Rio de Janeiro: [s.n.], 2011. Notas de aulas da disciplina Introdução à Ciência da Informação ministrada na Universidade Federal do Estado do Rio de Janeiro.

G1. Inventor do 'Obama on-line' diz que redes sociais só funcionam em mão dupla. 2010. Disponível em: <http://g1.globo.com/Noticias/Tecnologia/0,,MUL14660006174,00-INVENTOR+DO+OBAMA+ONLINE+DIZ+QUE+REDES >. Acesso em: 03 nov. 2017. 
INTERPARES 2 PROJECT. Diretrizes do Preservador. A preservação de documentos arquivísticos digitais: diretrizes para organizações. TEAM Brasil. Tradução: Arquivo Nacional e Câmara dos Deputados. 2002-2007a.

LOPES, Fernando Dias; BALDI, Mariana. Redes como perspectiva de análise e como estrutura de governança: uma análise das diferentes contribuições. Revista de Administração Pública, [s.1.], v. 43, n. 5, p.1007-1035, out. 2009. Disponível em: <http://www.scielo.br/pdf/rap/v43n5/v43n5a03.pdf>. Acesso em: 21 set. 2017.

MARTELETO, Regina Maria. Análise de redes sociais - aplicação nos estudos de transferência da informação. Ciência da Informação, [s.1.], v. 30, n. 1, p.71-81, abr. 2001. Disponível em: 〈http://www.scielo.br/pdf/ci/v30n1/a09v30n1.pdf>. Acesso em: 22 maio 2016.

MELLO, Patrícia Campos. Empresas contrataram disparos pró-Bolsonaro no WhatsApp, diz espanhol. Folha de São Paulo. São Paulo, 18 jul. 2019. Poder. Disponível em: <Empresas contrataram disparos pró-Bolsonaro no WhatsApp, diz espanhol>. Acesso em: 20 jul. 2019.

NORA, Pierre, Entre memória e história: a problemática dos lugares. Revista do Programa de Estudos Pós-Graduados em História e do Departamento de História. São Paulo, n.10, dez, 1993. Disponível em: <https://revistas.pucsp.br/revph/article/view/12101/8763> Acesso em: 23 ago. 2019

OBAMAWHITEHOUSE.GOV. The Obama Administration Digital Transition: Moving Forward. 2017. Disponível em:

<https://obamawhitehouse.archives.gov/blog/2017/01/17/obama-administration-digitaltransition-moving->. Acesso em: 02 nov. 2017.

RECUERO, Raquel. Redes sociais na internet: considerações iniciais. e Compós, [s.1.], v. 2, p.1-17, 2005. Disponível em: <http://www.ufrgs.br/limc/PDFs/redes_sociais.pdf>. Acesso em: 10 nov. 2016.

SANTOS, José Alex Soares. Teorias da aprendizagem: Comportamentalista, cognitivista e humanista. Revista Científica Sigma, Macapá, v. 2, n. 2, p. 96-110, 2006. Disponível em: $\langle$ https://www.iesap.edu.br/arquivo/Revista_SIGMA_2.pdf >. Acesso em: 22 maio 2018.

SHANNON, Claude Elwood. A Mathematical Theory of Communication. The Bell System Technical Journal, [s.1.], v. 27, p.379-423, jul./out. 1948. Disponível em: <http://math.harvard.edu/ ctm/home/text/others/shannon/entropy/entropy.pdf >. Acesso em: 9 jun. 2018. 